\title{
Article
}

\section{COVID-19 Impact on Adolescent 24 h Movement Behaviors}

\author{
Marie-Maude Dubuc ${ }^{1,2, *}$, Félix Berrigan ${ }^{1,2}$, Marylène Goudreault ${ }^{3}$, Sylvie Beaudoin ${ }^{1,2}$ and Sylvain Turcotte ${ }^{1,2}$ \\ 1 Faculté des Sciences de l'Activité Physique, Université de Sherbrooke, Sherbrooke, QC J1K 2R1, Canada; \\ felix.berrigan@usherbrooke.ca (F.B.); sylvie.beaudoin@usherbrooke.ca (S.B.); \\ sylvain.turcotte@usherbrooke.ca (S.T.) \\ 2 Kino-Québec Research Chair on the Adoption of a Physically Active Lifestyle in School Contexts, \\ Sherbrooke, QC J1K 2R1, Canada \\ 3 Direction Régionale de Santé Publique du CIUSSS du Centre-Sud-de-l'île-de-Montréal, \\ Montréal, QC H2L 4M1, Canada; marylene.goudreault.ccsmtl@ssss.gouv.qc.ca \\ * Correspondence: marie-maude.dubuc@usherbrooke.ca; Tel.: +1-819-821-8000 (ext. 65970)
}

Citation: Dubuc, M.-M.; Berrigan, F.; Goudreault, M.; Beaudoin, S.;

Turcotte, S. COVID-19 Impact on Adolescent $24 \mathrm{~h}$ Movement Behaviors Int. J. Environ. Res. Public Health 2021, 18, 9256. https://doi.org/10.3390/ ijerph18179256

Academic Editor: Daheia

J. Barr-Anderson

Received: 8 July 2021

Accepted: 30 August 2021

Published: 2 September 2021

Publisher's Note: MDPI stays neutral with regard to jurisdictional claims in published maps and institutional affiliations.

Copyright: (c) 2021 by the authors. Licensee MDPI, Basel, Switzerland. This article is an open access article distributed under the terms and conditions of the Creative Commons Attribution (CC BY) license (https:// creativecommons.org/licenses/by/ $4.0 /)$.

\begin{abstract}
This study aimed to examine the impact of the COVID-19 pandemic on the $24 \mathrm{~h}$ movement behaviors of adolescents. This was conducted to capture their evolution from February to December 2020, as well as to explore the use of technology for physical activity purposes by adolescents as a strategy to increase their physical activity during the pandemic. Physical activity, recreational screen time, sleep duration, and sleep quality were self-reported by 2661 adolescents using an online questionnaire. Participants also indicated, in comparison with the previous winter (regular in-class learning), how their different movement behaviors changed during the following 2020 periods: (1) spring (school closures), (2) summer (school break), and (3) autumn (hybrid learning). Finally, information about the use of technology during physical activity was collected. Results show that the $24 \mathrm{~h}$ movement behaviors of the participants varied across the different periods, and these variations were consistent with the restrictive measures imposed by the government. It was also observed that the negative effects of the COVID-19 pandemic on sleep duration and quality peaked in autumn. Finally, participants' physical activity levels were associated with the use of physical activity-related tools and applications. In conclusion, the restrictive measures due to the COVID-19 pandemic worsened the situation of the $24 \mathrm{~h}$ movement behaviors in adolescents, which has become critical.
\end{abstract}

Keywords: physical activity; screen time; sleep; sedentary behavior; secondary school; technology

\section{Introduction}

The Canadian $24 \mathrm{~h}$ movement guidelines [1] promote the importance of adopting an active lifestyle by addressing physical activity (PA) practice, sedentary behavior, and sleep habits. During adolescence, it is recommended to perform at least $60 \mathrm{~min}$ per day of moderate to vigorous PA, to limit recreational screen time to a maximum of $2 \mathrm{~h}$ per day, and to sleep steadily between 9 and $11 \mathrm{~h}$ per night (12-13 years old) or between 8 and $10 \mathrm{~h}$ per night (14-17 years old) [1]. It has been previously reported in Canada that children and adolescents struggle to follow these guidelines, with less than $20 \%$ of them successfully respecting these three recommendations [2,3].

The COVID-19 pandemic has led the three main levels of Canadian governments, namely federal, provincial, and municipal governments, to impose restrictive measures such as border closures, social distancing, quarantining, school closures, and more. As of the end of February 2021, one of the most impacted regions in Canada remains the Montreal area, with slightly more than $12 \%$ of the confirmed cases of infected persons in the country. In this area, adolescents experienced distance learning from 13 March 2020 until the end of June 2020 (summer break). During that period, a lockdown was imposed, forcing organized sports to stop or to continue virtually. Thereafter, restrictive measures decreased with the upcoming summer, allowing adolescents to practice organized sports with respect to various Public Health's measures to reduce the spread of the virus. In 
September 2020, adolescents from grades 7 to 11 (12 to 17 years old) were back in schools. However, a few weeks later, hybrid education, a mix of in-person and online activities, was provided to older students (grades 9 to 11; 14 to 17 years old). Most of the extracurricular activities and organized sports were forced to stop or to continue virtually once again.

These restrictive measures may have exacerbated adolescents' difficulties to follow the $24 \mathrm{~h}$ movement guidelines [3,4]. For example, preliminary evidence from a Canadian study conducted in parents of 1472 children and youth (5-17 years old) suggested that these measures had an adverse impact on youth PA levels, sedentary behaviors, and sleep [4]. Indeed, in the adolescent's subgroup (12-17 years old; $n=774)$, it was reported that only $0.6 \%$ of the $12-17$ years old met the three recommendations of the $24 \mathrm{~h}$ movement guidelines during the lockdown of April 2020 [4]. However, little is known about the evolution of adolescents' movement behaviors during the months following the spring 2020 lockdown. Furthermore, there is limited information about the strategies developed by adolescents during the pandemic to practice PA. Nevertheless, it was reported that the use of technology for PA purposes was positively associated with moderate to vigorous PA in adolescents and adults during the pandemic $[5,6]$.

Adolescents already represent a population struggling to adopt healthy movement behaviors, and the restrictions due to the COVID-19 pandemic appear to decrease their propensity to succeed in adopting healthy movement behaviors. Therefore, it seemed relevant to examine the impact of these restrictions on the $24 \mathrm{~h}$ movement of adolescents in one of the most affected communities in Canada. Thus, the present study aimed to examine the impact of the COVID-19 pandemic on PA practice, sedentary behavior associated with recreational screen time, and sleep habits of adolescents, to capture their evolution from February to December 2020 as well as to explore the use of technology for PA purposes as a strategy to increase their PA practice during the pandemic.

\section{Materials and Methods}

\subsection{Overview}

The results of this study are based on data collected within a collaborative research project involving University of Sherbrooke researchers, the Montreal Public Health, the school boards of the Montreal area, the City of Montreal, as well as public organizations engaged in the promotion of a physically active lifestyle in adolescents. Seventeen public secondary schools belonging to the school boards of the Montreal area accepted to participate in the study. Inclusion criteria for schools were: (1) to offer the regular secondary education program of the province of Quebec and (2) to serve grades 7 to 11 students, which represents the complete secondary education curriculum in the province. Seven of the participating secondary schools were English-language schools, while 10 of them were French-language schools. The data collection was performed during December 2020.

\subsection{Participants}

The study sample consisted of 2661 secondary school students, which included 1417 girls (53.3\%), 1154 boys (43.4\%), 33 gender-diverse (1.2\%), and 57 participants who did not indicate their gender $(2.1 \%)$, representing a $69 \%$ response rate. Inclusion criterion for participants was to be a regular student of one of the seventeen participating schools.

\subsection{Questionnaire}

All participants completed a 30 min online questionnaire (filled out either in English or French) during one of their classroom periods (virtual or in-class). Within the questionnaire, they were asked to qualitatively compare their movement behaviors (PA practice, screen recreational screen time, and sleep duration) during different periods of 2020 to "prior to the spring's lockdown period (before 13 March 2020)", referring to the last regular in-class learning period. Figure 1 presents the characteristics of these four different periods of 2020, which will thereafter be named winter, spring, summer, and autumn. Participants indicated if their PA practice, recreational screen time (excluding school-related screen 
time), and sleep duration varied during the spring, summer, and autumn in comparison to the previous winter on a five-level scale (from "decreased significantly" to "increased significantly"). They also indicated, using a question extracted from the Pittsburgh Sleep Quality Index [7], their sleep quality on a 4-point scale (from "very bad" to "very good") for each of the four periods of 2020 previously described. Thereafter, participants reported their actual PA practice (excluding physical education and health class) and recreational screen time in minutes per day for both weekdays and weekends as of December 2020. Using another question extracted from the Pittsburgh Sleep Quality Index [7], participants reported their actual sleep duration in hours per night for both weekdays and weekends. Finally, participants indicated if they had used technology when practicing PA over the last month, excluding in the physical education and health class context. When applicable, they specified what tool(s) or application(s) they used and the reason(s) why they used it (them). Thereafter, PA tools and applications were regrouped using the following categories: training exercises, pedometer, general health, weight loss, exercise inspiration, watches, tracking, entertainment during PA, and others.

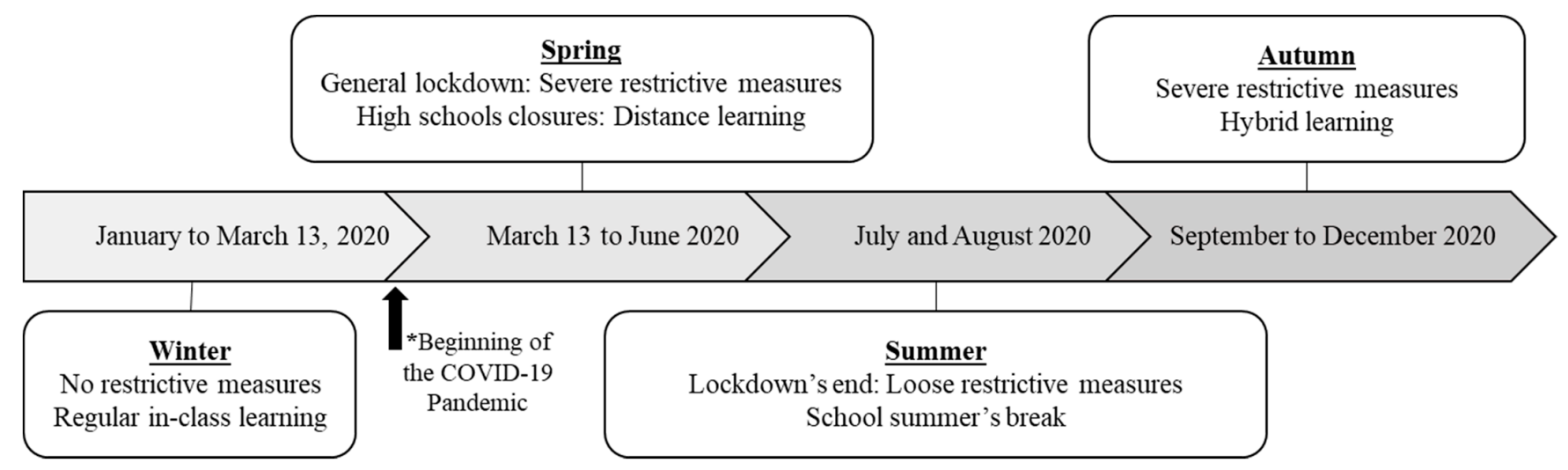

Figure 1. Timeline of the year 2020 in regard to the COVID-19 restrictive measures and the schooling situation. ${ }^{*}$ In the Montreal area, restrictive measures due to the COVID-19 pandemic started on 13 March 2020.

\subsection{Statistical Analysis}

Descriptive statistics were calculated for all study variables. A two-proportion bilateral z-test was performed to assess proportional differences in PA practice, recreational screen time, sleep duration, and sleep quality over the different periods of the 2020 year. Throughout the analyses, gender differences were assessed using chi square tests. Chi square tests were also performed to explore the association between the use of PA-related technology and the actual PA practice of participants. Significance was defined at $p<0.05$. Thereafter, $95 \%$ confidence intervals were also calculated to estimate the proportion of adolescents following the $24 \mathrm{~h}$ movement guidelines as of December 2020. Finally, a one-proportion bilateral z-test was performed to assess differences in the proportion of adolescents following the PA recommendations, the recreational screen time recommendations, and the sleep duration recommendations between the autumn 2020 and prior the COVID-19 pandemic (using data collected from a previous study by Roberts et al. [2]) Statistical analysis was performed using SPSS 27 for Windows (IBM Corp., New York, NY, USA).

\section{Results}

\subsection{Evolution of the $24 \mathrm{~h}$ Movement Behaviors}

Most of the participants (55\%) reported a decrease in their PA practice during the spring of either a slight decrease (29\%) or a significant decrease (26\%), as shown in Figure 2. During that same period, $18 \%$ of the participants reported an increase in their PA practice of either a slight increase (11\%) or a significant increase (7\%). In the summer, $30 \%$ of the 
participants reported a decrease in their PA practice in comparison with the winter $(21 \%$ reported a slight decrease and $9 \%$ a significant decrease), while $42 \%$ of them reported an increase ( $28 \%$ reported a slight increase and $14 \%$ a significant increase). In the autumn, $40 \%$ of the participants experienced a decrease in their PA practice compared to the winter, with $25 \%$ of them reporting a slight decrease and $15 \%$ a significant decrease. Over that same period, $30 \%$ of the participants reported an increase in their PA practice compared to the winter, with either a slight increase $(22 \%)$ or a significant increase $(8 \%)$. It should be noted that a significant gender effect was only observed during the spring, while a larger proportion of girls reported experiencing changes in their PA practice than boys or gender-diverse participants $(77 \%, 71 \%$, and $61 \%$, respectively; $p<0.001)$.

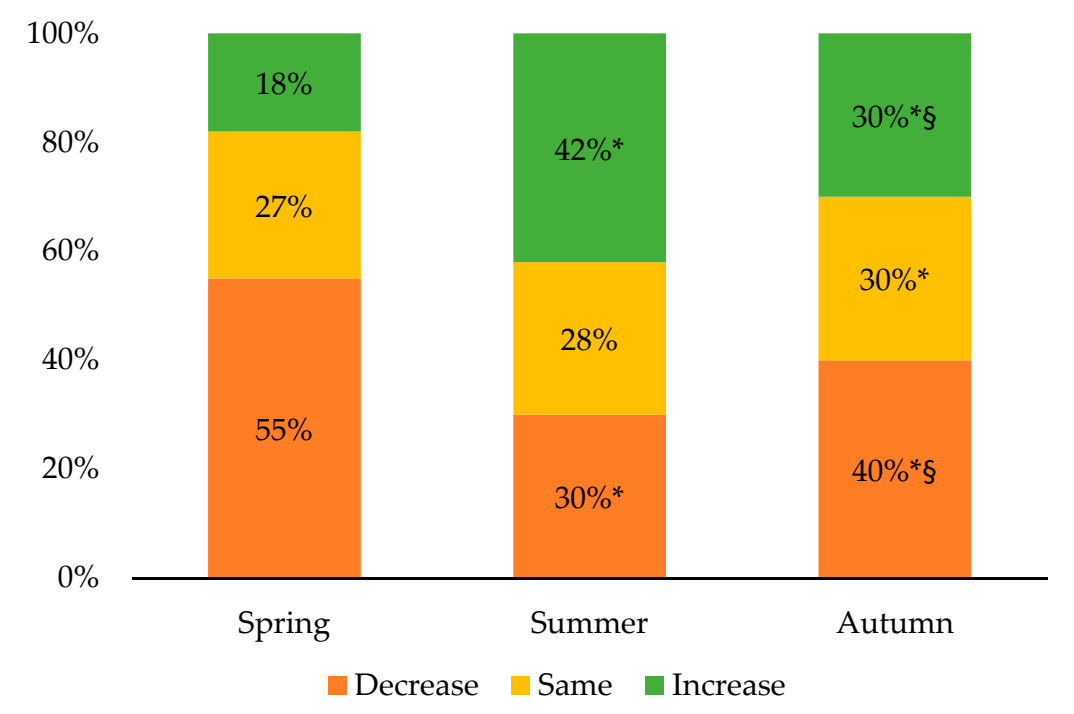

Figure 2. Evolution of physical activity practice compared to the winter 2020. * Significantly different from the spring; ${ }^{\S}$ Significantly different from the summer; $p<0.01$.

Figure 3 presents the evolution of the participants' recreational screen time from the spring to the autumn in comparison to the winter. Most of the participants had increased their recreational screen time during the spring $(68 \%)$, reporting either a slight increase $(25 \%)$ or a significant increase $(43 \%)$. Few participants $(9 \%)$ reported a decrease in their recreational screen time during that same period, with $5 \%$ of them reporting a slight decrease and $4 \%$ a significant decrease. A significant gender effect was also observed during the spring, while a greater proportion of girls and gender-diverse participants reported experiencing an increased recreational screen time than boys $(72 \%, 71 \%$, and $63 \%$, respectively; $p<0.001)$. In the summer, $48 \%$ of the participants reported an increase $(24 \%$ reported a slight increase and $24 \%$ a significant increase), while $21 \%$ of them reported a decrease in their recreational screen time in comparison with the winter (16\% reported a slight decrease and $5 \%$ a significant decrease). Almost half of the participants (48\%) were still reporting an increased recreational screen time in the autumn compared to the winter, with $25 \%$ of them reporting a slight increase and $23 \%$ a significant increase. Over that same period, $20 \%$ of the participants reported a decrease in their recreational screen time compared to the winter, as either a slight decrease $(14 \%)$ or a significant decrease $(6 \%)$. During both the summer and the autumn, a larger proportion of girls and gender-diverse participants reported continuing to experiment with more recreational screen time than during the winter (both $p=0.001$ ). 


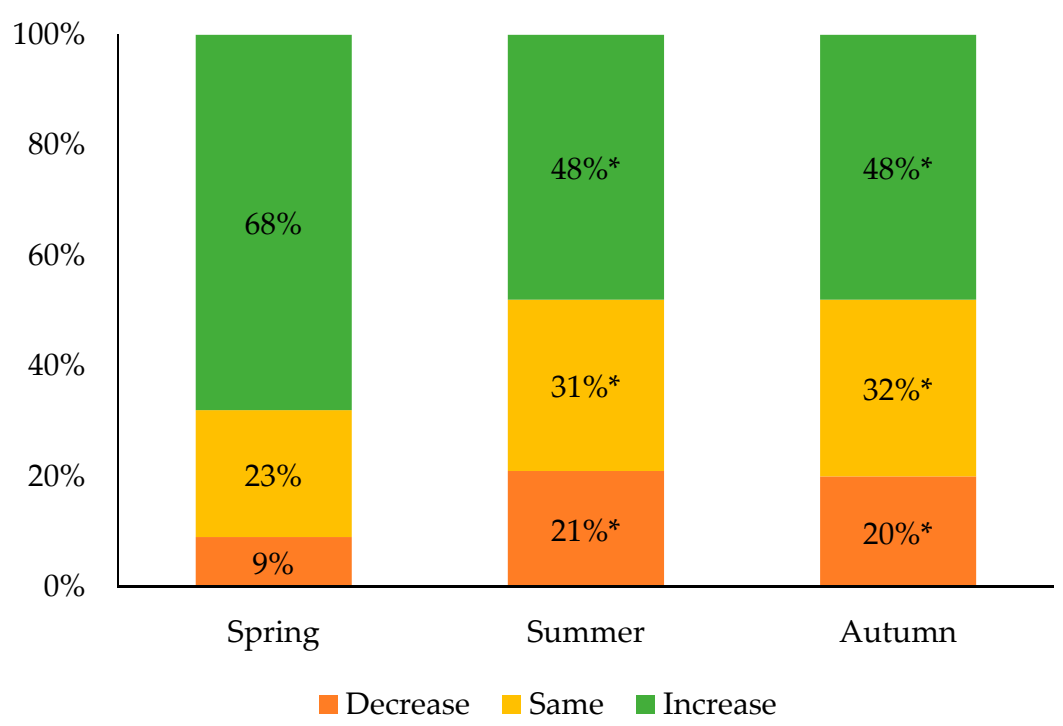

Figure 3. Evolution of recreational screen time compared to the winter $2020 .{ }^{*}$ Significantly different from the spring; $p<0.001$.

The evolution of the sleep duration from the spring to the autumn in comparison to the winter is shown in Figure 4. During the spring, $40 \%$ of the participants reported an increase in their sleep duration of either a slight increase (17\%) or a significant increase $(23 \%)$. During that same period, $31 \%$ of the participants reported a decrease in their sleep duration, of either a slight decrease (13\%) or a significant decrease $(18 \%)$. In the summer, $39 \%$ of the participants had increased their sleep duration in comparison with the winter, reporting either a slight increase $(20 \%)$ or a significant increase (19\%). Many participants $(29 \%)$ reported a decrease in their sleep duration during that same period, with $15 \%$ of them reporting a slight decrease and $14 \%$ a significant decrease. A significantly higher proportion of the participants ( $49 \%$ ) reported a decrease in their sleep duration during the autumn compared to the winter of either a slight decrease $(25 \%)$ or a significant decrease $(24 \%)$. During that same period, $20 \%$ of the participants reported an increase in their sleep duration, with either a slight increase $(13 \%)$ or a significant increase $(7 \%)$. Again, a significant gender effect was observed for the three different periods, with a greater proportion of girls reported that they were experiencing changes in their sleep duration than boys or gender-diverse participants (all $p<0.001$ ).

Moreover, the evolution of the sleep quality through the 2020 year is shown in Figure 5. That is, during the winter, $73 \%$ of the participants had experienced a rather good (55\%) or a very good $(18 \%)$ sleep quality, while $27 \%$ of them had experienced a rather bad $(19 \%)$ or very bad sleep quality ( $8 \%$ ). In the spring, $66 \%$ of the participants reported a rather good $(38 \%)$ or a very good $(28 \%)$ sleep quality, while $34 \%$ of them reported a rather bad $(20 \%)$ or a very bad (14\%) sleep quality. Most of the participants $(72 \%)$ indicated that their sleep quality was rather good $(40 \%)$ or very good $(32 \%)$ during the summer. For the same period, a rather bad $(17 \%)$ or a very bad (11\%) sleep quality was reported by $28 \%$ of them. Finally, the sleep quality was at its lower level of the year during the autumn. Indeed, $47 \%$ of the participants had experienced bad sleep quality in the autumn, with $28 \%$ of them reporting a rather bad and $19 \%$ reporting a very bad sleep quality. During that same period, $39 \%$ of the participants reported a rather good and $14 \%$ reported a very good sleep quality, for a total of $53 \%$ of the participants that had experienced good sleep quality in the autumn. Compared to the winter, decreases in sleep quality were more commonly reported during the autumn than during the spring $(p<0.001)$. A greater proportion of gender-diverse participants had experienced bad quality sleep than girls or boys for these four different periods $(p<0.001)$. 


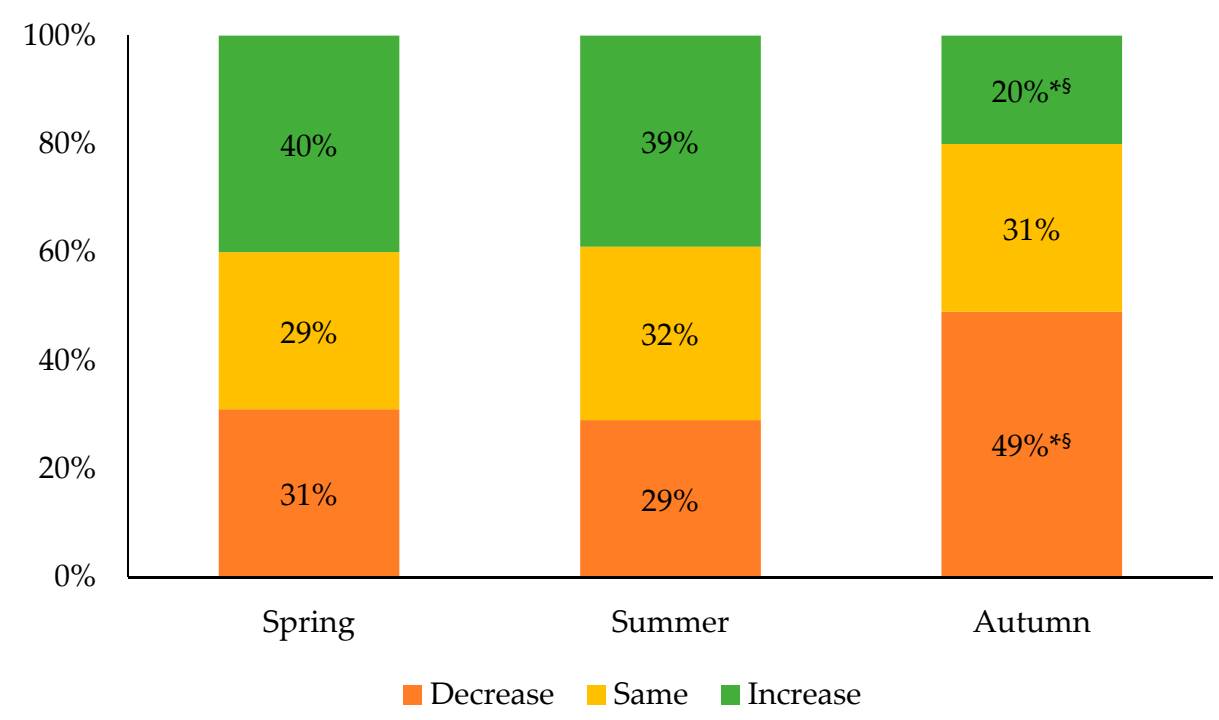

Figure 4. Evolution of sleep duration compared to the winter 2020. * Significantly different from the spring; ${ }^{\S}$ significantly different from the summer; $p<0.01$.

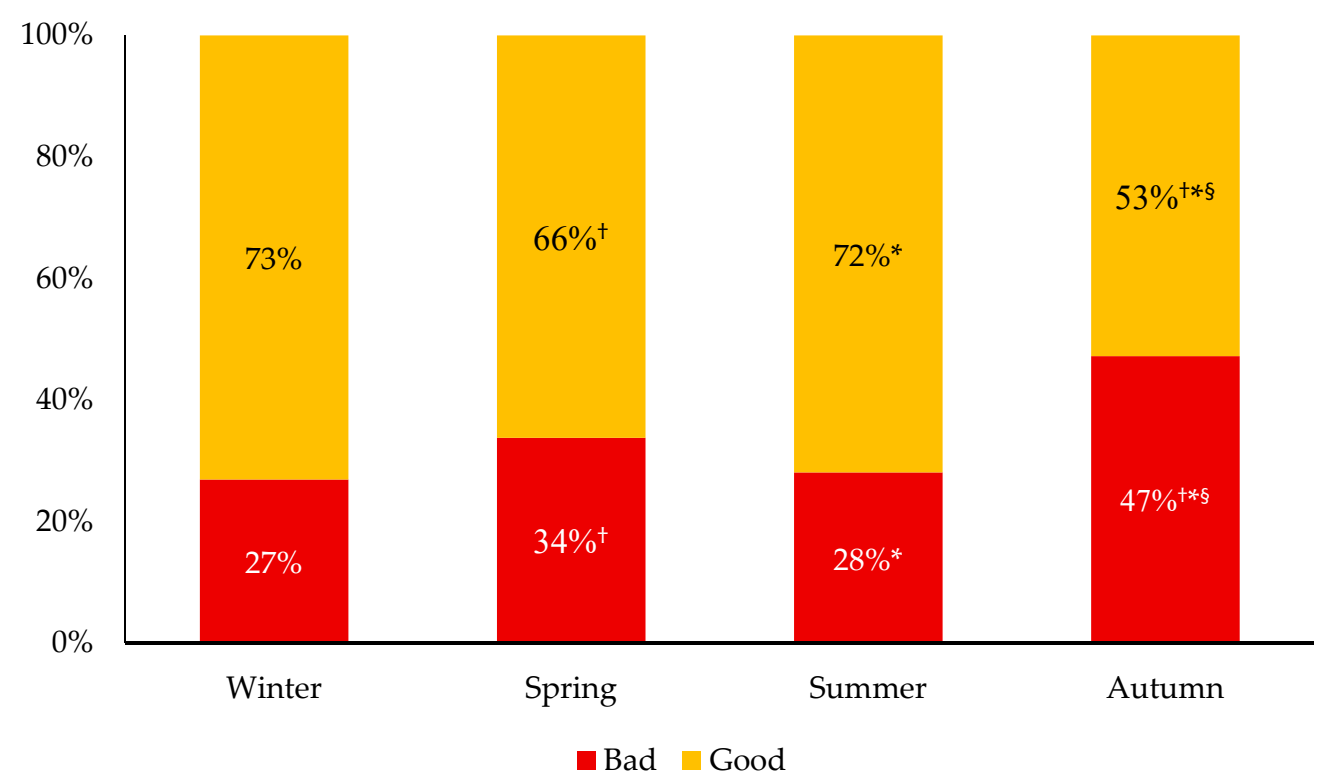

Figure 5. Evolution of sleep quality from the winter 2020 to the autumn $2020 .{ }^{\dagger}$ Significantly different from the winter; ${ }^{*}$ significantly different from the spring; $\S$ significantly different from the summer; $p<0.001$.

\subsection{Meeting the $24 \mathrm{~h}$ Movement Recommendations}

The proportion of participants meeting each of the three $24 \mathrm{~h}$ movement behavior guidelines as well as the estimation of the proportion of adolescents following them as of December 2020 are presented in Table 1. On weekdays, $1.1 \%$ of the participants followed the recommendations for PA practice in their recreational screen time as well as for sleep duration. On weekends, this proportion was $1.4 \%$. Participants meeting all of the three movement behavior recommendations on both weekdays and weekends represent $0.2 \%$ of the sample. Moreover, $50.0 \%$ of the participants reported meeting none of the three recommendations on weekdays and $41.7 \%$ on the weekend. That is, $26.3 \%$ of the participants reported meeting none of these recommendations, whether on weekdays or on weekends. It should be noted that $37.1 \%$ of the participants reported practicing less than 20 min of PA per weekday, compared to $41.2 \%$ per weekend day. 
Table 1. Proportion of adolescents meeting the physical activity, recreational screen time, and sleep duration recommendations as of December 2020.

\begin{tabular}{|c|c|c|c|c|c|c|c|c|}
\hline \multirow[b]{2}{*}{$\begin{array}{l}24 \text { h Movement Behavior } \\
\text { Recommendations }\end{array}$} & \multicolumn{4}{|c|}{ Weekdays } & \multicolumn{4}{|c|}{ Weekend } \\
\hline & $\begin{array}{l}\text { All Students } \\
n=2661\end{array}$ & $\begin{array}{c}\text { Girls } \\
n=1417\end{array}$ & $\begin{array}{c}\text { Boys } \\
n=1154\end{array}$ & $\begin{array}{c}\text { Gender-Diverse } \\
n=33\end{array}$ & $\begin{array}{l}\text { All Students } \\
n=2661\end{array}$ & $\begin{array}{c}\text { Girls } \\
n=1417\end{array}$ & $\begin{array}{c}\text { Boys } \\
n=1154\end{array}$ & $\begin{array}{l}\text { Gender-Diverse } \\
\qquad n=33\end{array}$ \\
\hline \multicolumn{9}{|l|}{ Specific recommendations } \\
\hline Physical activity ( $\geq 60 \mathrm{~min} /$ day) & $\begin{array}{c}18.3 \\
{[16.8-19.8]}\end{array}$ & $\begin{array}{c}15.8 \\
{[13.9-17.7]}\end{array}$ & $\begin{array}{c}21.2 \\
{[18.8-23.6]}\end{array}$ & $\begin{array}{c}28.1^{\S} \\
{[12.5-43.7]}\end{array}$ & $\begin{array}{c}20.1 \\
{[18.6-21.6]}\end{array}$ & $\begin{array}{c}15.2 \\
{[13.3-17.1]}\end{array}$ & $\begin{array}{c}25.9 \\
{[23.3-28.5]}\end{array}$ & $\begin{array}{c}34.4^{\S} \\
{[17.9-50.9]}\end{array}$ \\
\hline $\begin{array}{l}\text { Recreational screen time }(\leq 2 \\
\mathrm{h} / \text { day })\end{array}$ & $\begin{array}{c}27.4 \\
{[25.6-29.2]}\end{array}$ & $\begin{array}{c}25.0 \\
{[22.7-27.3]}\end{array}$ & $\begin{array}{c}31.0 \\
{[28.2-33.8]}\end{array}$ & $\begin{array}{c}13.3 \S \\
{[11.5-25.5]}\end{array}$ & $\begin{array}{c}14.0 \\
{[12.6-15.4]}\end{array}$ & $\begin{array}{c}13.2 \\
{[11.4-15.0]}\end{array}$ & $\begin{array}{c}15.0 \\
{[12.8-17.2]}\end{array}$ & $\begin{array}{c}6.7 \\
{[0.0-15.6]}\end{array}$ \\
\hline Sleep duration (8 to $11 \mathrm{~h} /$ night $^{*}$ ) & $\begin{array}{c}18.4 \\
{[16.9-19.9]}\end{array}$ & $\begin{array}{c}15.2 \\
{[13.3-17.1]}\end{array}$ & $\begin{array}{c}23.4 \\
{[20.8-26.0]}\end{array}$ & $\begin{array}{c}6.5^{\S} \\
{[0.0-15.2]}\end{array}$ & $\begin{array}{c}39.4 \\
{[37.5-41.3]}\end{array}$ & $\begin{array}{c}38.1 \\
{[35.5-40.7]}\end{array}$ & $\begin{array}{c}42.2 \\
{[39.2-45.2]}\end{array}$ & $\begin{array}{c}29.0 \S \\
{[13.0-45.0]}\end{array}$ \\
\hline $\begin{array}{l}\text { Combination of recommendations } \\
\text { Physical activity and recreational } \\
\text { screen time }\end{array}$ & $\begin{array}{c}5.0 \\
{[4.2-5.8]}\end{array}$ & $\begin{array}{c}3.8 \\
{[2.8-4.8]}\end{array}$ & $\begin{array}{c}6.5 \\
{[5.1-7.9]}\end{array}$ & $\begin{array}{c}6.1^{\S} \\
{[0.0-14.5]}\end{array}$ & $\begin{array}{c}3.0 \\
{[2.3-3.7]}\end{array}$ & $\begin{array}{c}1.7 \\
{[1.0-2.4]}\end{array}$ & $\begin{array}{c}4.5 \\
{[3.3-5.7]}\end{array}$ & $\begin{array}{c}3.0^{\S} \\
{[0.0-8.8]}\end{array}$ \\
\hline $\begin{array}{l}\text { Physical activity and sleep } \\
\text { duration }\end{array}$ & $\begin{array}{c}3.4 \\
{[2.7-4.1]}\end{array}$ & $\begin{array}{c}1.8 \\
{[1.1-2.5]}\end{array}$ & $\begin{array}{c}5.3 \\
{[4.0-6.6]}\end{array}$ & $\begin{array}{c}3.0 \S \\
{[0.0-8.8]}\end{array}$ & $\begin{array}{c}7.8 \\
{[6.8-8.8]}\end{array}$ & $\begin{array}{c}5.9 \\
{[4.7-7.1]}\end{array}$ & $\begin{array}{c}10.5 \\
{[8.7-12.3]}\end{array}$ & $\begin{array}{c}6.1^{\S} \\
{[0.0-14.3]}\end{array}$ \\
\hline $\begin{array}{l}\text { Recreational screen time and } \\
\text { sleep duration }\end{array}$ & $\begin{array}{c}6.1 \\
{[5.2-7.0]}\end{array}$ & $\begin{array}{c}4.8 \\
{[3.7-5.9]}\end{array}$ & $\begin{array}{c}8.2 \\
{[6.5-9.9]}\end{array}$ & $\begin{array}{c}0.0 \S \\
{[0.0-2.9]}\end{array}$ & $\begin{array}{c}5.1 \\
{[4.2-6.0]}\end{array}$ & $\begin{array}{c}4.4 \\
{[3.3-5.5]}\end{array}$ & $\begin{array}{c}6.3 \\
{[4.8-7.8]}\end{array}$ & $\begin{array}{c}0.0 \S \\
{[0.0-2.9]}\end{array}$ \\
\hline All three recommendations & $\begin{array}{c}1.1 \\
{[0.7-1.5]}\end{array}$ & $\begin{array}{c}0.5 \\
{[0.1-0.9]}\end{array}$ & $\begin{array}{c}1.9 \\
{[1.1-2.7]}\end{array}$ & $\begin{array}{c}0.0 \S \\
{[0.0-2.9]}\end{array}$ & $\begin{array}{c}1.4 \\
{[1.0-1.8]}\end{array}$ & $\begin{array}{c}0.6 \\
{[0.2-1.0]}\end{array}$ & $\begin{array}{c}2.5 \S \\
{[1.6-3.4]}\end{array}$ & $\begin{array}{c}0.0 \S \\
{[0.0-2.9]}\end{array}$ \\
\hline
\end{tabular}

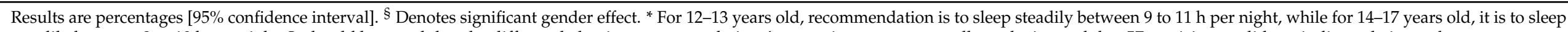
steadily between 8 to $10 \mathrm{~h}$ per night. It should be noted that the different behavior recommendations' categories are not mutually exclusive and that 57 participants did not indicate their gender. 
Regarding the use of technology while practicing PA, $40.8 \%$ of the participants reported using a tool or an application over the last month. An association between the use of a PA-related technology and the actual PA level of the participants was observed $(p<0.001)$, as shown in Figure 6. That is, lower proportions of participants using those types of tools or applications reported practicing less than $20 \mathrm{~min}$ of PA per day, for both during the week and the weekend, compared to other participants. Moreover, higher proportions of participants who used a PA-related tool or application reported meeting the PA recommendation, for both the week and weekend, compared to other participants (see Figure 7). The most popular categories of PA tools and applications were exercise inspiration $(22.6 \%)$, tracking $(18.9 \%)$, training exercises $(14.1 \%)$, and watches $(11.9 \%)$. Participants indicated using these technologies to track their PA $(46.9 \%)$, to track their progress $(32.1 \%)$, to find suggestions of new exercises $(28.4 \%)$, to pass the time when they were bored $(25.9 \%)$, and to count the calories burned while exercising $(19.5 \%)$.

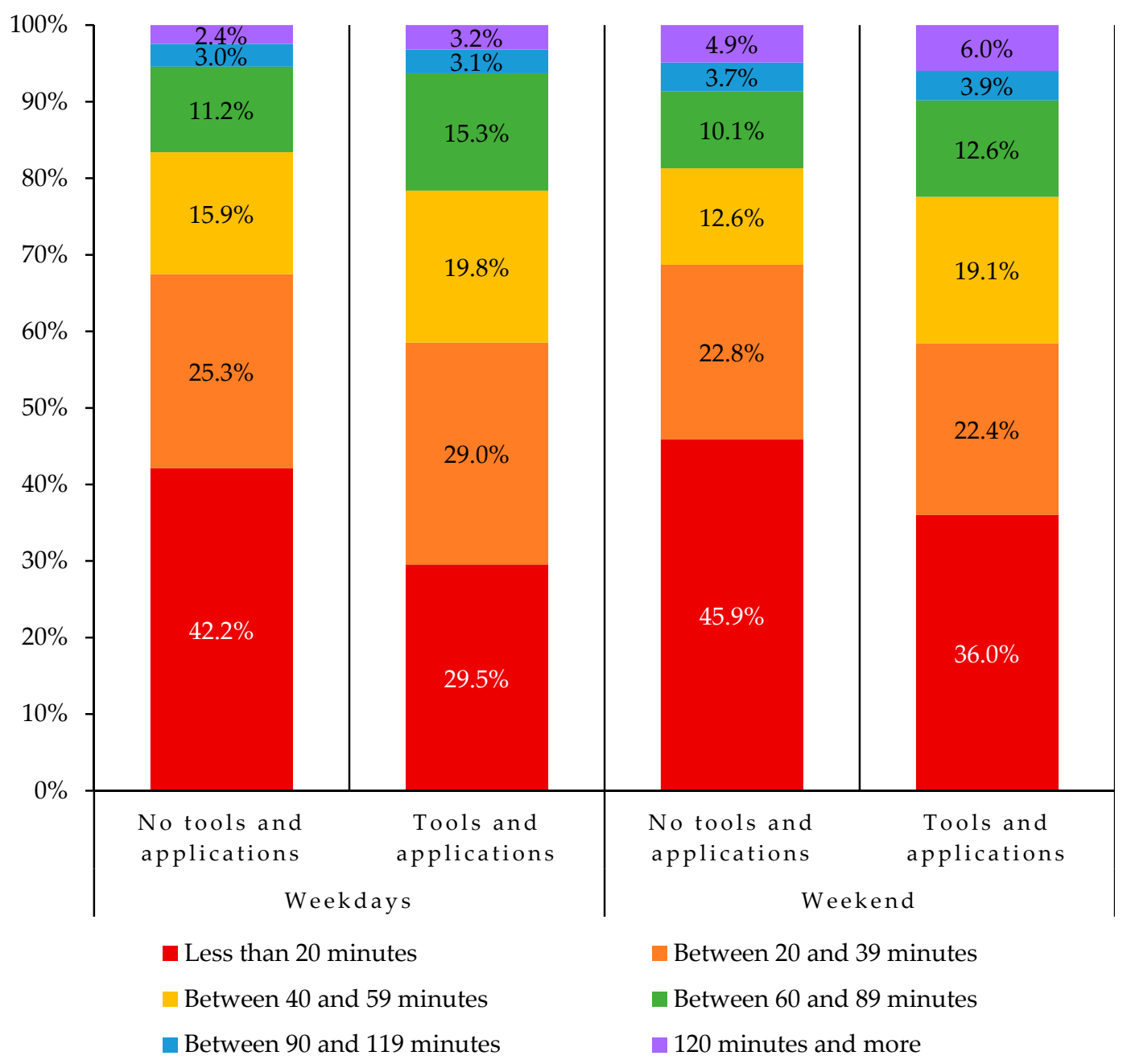

Figure 6. Association between the use of physical activity-related tools and applications and the daily physical activity in adolescents. Pearson chi square $p$ value $<0.001$ for this association on both weekdays and weekend. 


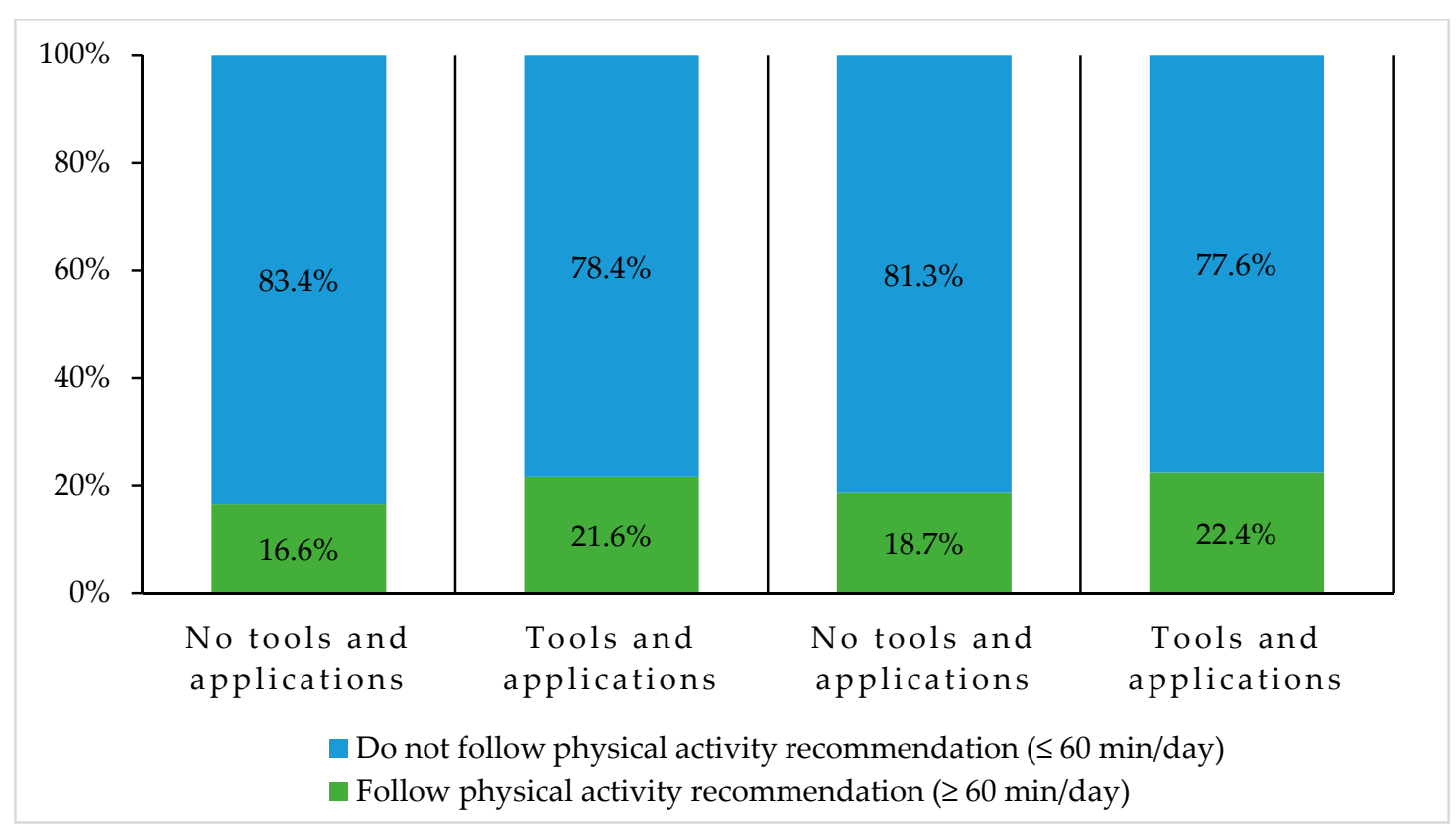

Figure 7. Association between the use of physical activity-related tools and applications, and the respect of the physical activity recommendation in adolescents. Pearson chi square $p$ value $<0.05$ for this association on both weekdays and weekend.

The proportions of participants reporting more than $4 \mathrm{~h}$ per day of recreational screen time on weekdays and weekends were $37.4 \%$ and $58.1 \%$, respectively. Concerning sleep duration, $34.4 \%$ of the participants reported sleeping less than $7 \mathrm{~h}$ per night on weekdays, in comparison to $20.3 \%$ on the weekend. Furthermore, when compared to the results of a Canadian study performed before the COVID-19 pandemic [2], there were significantly less adolescents meeting the three $24 \mathrm{~h}$ movement behavior guidelines during the autumn 2020 than prior to the lockdown, whether taken two by two or all together (all $p<0.001)$. For example, it was observed in 2017 that $5.5 \%$ of a sample of 1126 12- to 17-year-old Canadians met all three recommendations, while $17.1 \%$ met none of them [2]. When taken individually, there were also less adolescents meeting the PA and the sleep duration recommendations in 2020 compared to 2017 (both $p<0.001$ ), but no difference was observed for the screen time $(p=0.24)$. That is, there were respectively $24.4 \%, 68.1 \%$, and $28.1 \%$ of adolescents meeting the PA, sleep duration, and screen time recommendations prior the COVID-19 pandemic. Finally, our results indicate that less than $0.5 \%$ (95\% CI [0.000-0.004]) of adolescents met the $24 \mathrm{~h}$ movement behavior guidelines as of December 2020.

\section{Discussion}

\subsection{Evolution of the $24 \mathrm{~h}$ Movement Behaviors}

The present study aimed to firstly draw the evolution from February 2020 to December 2020 of the PA practice, recreational screen time, and sleep habits of adolescents. Our results indicate that the $24 \mathrm{~h}$ movement behaviors of the participants varied across the different seasons, and that these variations are consistent with the restrictive measures implemented by the Canadian governments for PA practice and recreational screen time. That is, compared to winter, a decrease in PA practice as well as an increase in recreational screen time were observed during the spring for more than half of the participants. These results are consistent with previous results $[4,8,9]$ and seem to be directly associated with the imposed lockdown. During the summer, while restrictive measures were loosened which allowed organized sports to resume, an improvement in PA practice and recreational screen time compared to during the spring was observed. During the autumn, in comparison with the summer, the PA practice had decreased again, while the recreational screen time had remained similar. That is, in autumn, $40 \%$ of the participants were still 
experiencing a decrease in their PA practice compared to the winter, while $48 \%$ of the participants were still using screens for recreational use more often than during the winter. Severe restrictive measures were imposed in autumn, including hybrid learning at school for older students, organized sports interruption, and social distancing. Results of the present study indicate that a large proportion of adolescents were unable to adapt their PA practice and recreational screen time habits to get back to their usual behaviors in terms of time per day, while having to comply with the restrictive measures imposed due to the COVID-19 pandemic. However, it should be noted that the variations observed in adolescents' behaviors may be partly due to the change across seasons itself, and, therefore, could have been partially observed independently of the COVID-19 pandemic. Strategies leading to movement behaviors changes during these exceptional times should be immediately implemented or enhanced, in order to favor the adoption of a structured day in line with the $24 \mathrm{~h}$ movement guidelines, such as street closures to allow PA practice while respecting social distancing, parental education about breaking up sedentary behavior, PA challenges with family and neighborhood, and so on [8].

Interestingly, the evolution of the sleep quantity and quality of the participants from the winter to the autumn 2020 differs from their PA practice and recreational screen time evolution. That is, it was observed that a larger proportion of adolescents had increased their sleep duration during the spring. This is in line with previous studies reporting more time sleeping in adolescents during the spring lockdown $[4,10,11]$, and could be explained by the school closures, allowing adolescents to sleep longer in the morning. Moreover, no differences between the summer and the spring were observed in sleep duration. However, nearly half of the participants reported a decrease in their sleep duration during the autumn compared to the winter. A possible explanation could be a delayed sleep timing which may be caused by the unscheduled sleep (i.e., no specific bed or wake time) experienced during the spring and the summer 2020 [8]. The PA practice decrease and the recreational screen time increase may also be part of the explanation, as they are both associated with poorer sleep [12-14]. Thus, results of the present study support the 'Structured Days Hypothesis' [15], which claims that the structured environment usually offered by school helps students to adopt more healthy behaviors, including PA, recreational screen time, and sleep patterns. Furthermore, sleep quality was mostly altered during the autumn, with $47 \%$ of the participants reporting bad quality sleep compared to $27 \%$ in the winter, $34 \%$ in the spring, and $28 \%$ in the summer. That is, results of the present study suggest that the COVID-19 pandemic direct and indirect effects may have impacted sleep duration and quality in adolescents, and that these effects seemed to arise several months after the beginning of the pandemic, which might be underestimated to this day.

\subsection{Meeting the $24 \mathrm{~h}$ Movement Recommendations}

This study also aimed to estimate the PA levels, recreational screen time, and sleep duration of adolescents as of December 2020. That is, our results indicate that less than $1 \%$ of adolescents was able to follow the three recommendations of the $24 \mathrm{~h}$ movement guidelines on both weekdays and weekends. Moreover, $26.3 \%$ of the participants failed to meet a single recommendation on weekdays or on weekends, and this proportion rises to $50.0 \%$ when considering weekdays only. These results are in line with previous Canadian studies conducted during the spring lockdown [3,4], and suggest that no improvement was made regarding the $24 \mathrm{~h}$ movement behaviors in adolescents between April 2020 and December 2020. The sustained reduction observed in the healthy movement behaviors are certainly critical and might lead to important adverse impacts on adolescents' development [13]. Therefore, substantial effort is required to promote healthy movement behaviors and to provide resources to support the adolescents, their parents, the secondary school stakeholders, as well as the community.

Furthermore, as adolescents already struggled to follow the $24 \mathrm{~h}$ movement guidelines prior to the COVID-19 pandemic [2,3], our results suggest that the practice of PA in adolescents depends to a large extent on organized PA, and that they have little autonomy. 
Based on these results, immediate solutions are needed to favor the adolescents' PA practice despite the restrictions in place. That is, our results indicated that PA-related tools and applications could be an avenue to explore in this context, to enhance PA participation in adolescents. Previous studies reported similar findings among adolescents and adults $[5,6]$. Moreover, as adolescents' trips outside the home are still almost exclusively to go to school, exceptional measures favoring the adoption of a healthy and physically active lifestyle should be implemented in secondary schools as soon as possible. For example, flexible school schedules allowing adolescents to practice PAs within both their in-class and athome school days, as well as the prescription of home-based exercise programs could be implemented [16]. Furthermore, our results indicated that a substantial proportion of adolescents had perceived an increase in their PA practice despite the restrictive measures in place, such as the interruption of organized sports. This result raises questions on what happened with these adolescents, as well as on how actual organized sports, including at-school activities, ensure that they meet all adolescents' needs in terms of PA. Further studies should consider examining these questions, to help find more solutions. Outdoor activities should also be encouraged in both in-school and at-home settings in order to favor PA practice $[13,17]$. Finally, measures aiming to increase the autonomy of all adolescents concerning the adoption of a healthy and physically active lifestyle, such as physical education and health classes, should be magnified, and new measures should be developed to counteract the actual situation $[18,19]$.

\subsection{Limitations}

There were some limitations in the present study. First, our findings are limited to a population of students from public secondary schools in Montreal, Canada. Nonetheless, our results are strengthened by studying a homogenous population in a very large sample size. Second, as the participants completed the questionnaire in December 2020 and were asked to compare their behavior during specified periods of 2020 with their behavior prior to the onset of the COVID-19 pandemic, their answers may be subject to recall biases. Therefore, results of the present study should be interpreted with caution. Finally, another limitation was the use of self-reported measures of lifestyle habits. However, as the use of self-reported measures is usually associated with the social desirability bias [20], it is even more worrisome to observe these catastrophic results.

\section{Conclusions}

Results of the present study suggest that the restrictive measures due to the COVID19 pandemic contributed to the worsening of the already worrying situation of the $24 \mathrm{~h}$ movement behaviors in adolescents, making it harmful for the adolescent's health and development. Indeed, significant proportions of adolescents practice less PA, spend more recreational time on screens, and experience poorer sleep than prior to the spring lockdown. Moreover, as of December 2020, nearly none of the adolescents met the three recommendations of the $24 \mathrm{~h}$ movement guidelines, becoming a critical issue. To prevent the appearance of developmental problems in adolescents, policymakers, educators, families as well as the community should immediately take strong and direct actions to favor the adoption of a healthy and physically active lifestyle in adolescents during and after the COVID-19 pandemic.

Author Contributions: Conceptualization, M.-M.D., F.B., M.G., S.B. and S.T.; methodology, M.-M.D., F.B., M.G., S.B. and S.T.; formal analysis, M.-M.D.; investigation, M.-M.D. and M.G.; writing-original draft preparation, M.-M.D.; writing-review and editing, F.B., M.G., S.B. and S.T. All authors have read and agreed to the published version of the manuscript.

Funding: This study was funded by Sport et Loisir de l'île de Montréal, a regional and non-profit organization, through the Politique gouvernementale de prévention en santé. The funding source was not involved in the study design, collection, interpretation, and analysis of the data as well as the writing of the manuscript. 
Institutional Review Board Statement: This study was conducted according to the guidelines of the Declaration of Helsinki, and approved by the research ethics committee on addictions, social inequalities, and public health of the Montreal Public Health's department (DIS-1920-10; approved on 9 November 2020).

Informed Consent Statement: All participants and their parents or guardians were fully informed about the nature, goals, and protocols of the study and gave their informed consent.

Data Availability Statement: The data presented in this study are available on request from the corresponding author. The data are not publicly available due to privacy and ethical considerations.

Acknowledgments: We would like to thank Sport et loisir de l'île de Montréal, the school boards of the region of Montreal, the three regional organizations of the Réseau du Sport Étudiant du Québec, the City of Montreal, Montréal physiquement active as well as all the participants.

Conflicts of Interest: The authors declare no conflict of interest.

\section{References}

1. Tremblay, M.S.; Carson, V.; Chaput, J.P.; Connor Gorber, S.; Dinh, T.; Duggan, M.; Faulkner, G.; Gray, C.E.; Gruber, R.; Janson, K.; et al. Canadian 24-Hour Movement Guidelines for children and youth: An integration of physical activity, sedentary behaviour, and sleep. Appl. Physiol. Nutr. Metab. 2016, 41, S311-S327. [CrossRef] [PubMed]

2. Carson, V.; Chaput, J.P.; Janssen, I.; Tremblay, M.S. Health Associations with meeting new 24-Hour Movement Guidelines for Canadian children and youth. Prev. Med. 2017, 95, 7-13. [CrossRef] [PubMed]

3. ParticipACTION. The role of the family in the physical activity, sedentary and sleep behaviours of children and youth. In The 2020 ParticipACTION Report Card on Physical Activity for Children and Youth; ParticipACTION: Toronto, ON, Canada, 2020.

4. Moore, S.A.; Faulkner, G.; Rhodes, R.E.; Brussoni, M.; Chulak-Bozzer, T.; Ferguson, L.J.; Mitra, R.; O’Reilly, N.; Spence, J.C.; Vanderloo, L.M.; et al. Impact of the COVID-19 Virus outbreak on movement and play behaviours of Canadian children and youth: A national survey. Int. J. Behav. Nutr. Phys. Act. 2020, 17, 85. [CrossRef] [PubMed]

5. Parker, K.; Uddin, R.; Ridgers, N.D.; Brown, H.; Veitch, J.; Salmon, J.; Timperio, A.; Sahlqvist, S.; Cassar, S.; Toffoletti, K.; et al. The use of digital platforms for adults' and adolescents' physical activity during the COVID-19 pandemic (Our Life at Home): Survey study. J. Med. Internet Res. 2021, 23, e23389. [CrossRef] [PubMed]

6. Yang, Y.; Koenigstorfer, J. Determinants of physical activity maintenance during the COVID-19 Pandemic: A focus on fitness apps. Transl. Behav. Med. 2020, 10, 835-842. [CrossRef] [PubMed]

7. Buysse, D.J.; Reynolds, C.F., III; Monk, T.H.; Berman, S.R.; Kupfer, D.J. The Pittsburgh Sleep Quality Index: A new instrument for psychiatric practice and research. Psychiatry Res. 1989, 28, 193-213. [CrossRef]

8. Bates, L.C.; Zieff, G.; Stanford, K.; Moore, J.B.; Kerr, Z.Y.; Hanson, E.D.; Barone Gibbs, B.; Kline, C.E.; Stoner, L. COVID-19 Impact on behaviors across the 24-hour day in children and adolescents: Physical activity, sedentary behavior, and sleep. Children 2020, 7, 138. [CrossRef] [PubMed]

9. Munasinghe, S.; Sperandei, S.; Freebairn, L.; Conroy, E.; Jani, H.; Marjanovic, S.; Page, A. The impact of physical distancing policies during the COVID-19 pandemic on health and well-being among Australian adolescents. J. Adolesc. Health 2020, 67, 653-661. [CrossRef] [PubMed]

10. Dutta, K.; Mukherjee, R.; Sen, D.; Sahu, S. Effect of COVID-19 lockdown on sleep behavior and screen exposure time: An observational study among Indian school children. Biol. Rhythm Res. 2020, 1-12. [CrossRef]

11. Pietrobelli, A.; Pecoraro, L.; Ferruzzi, A.; Heo, M.; Faith, M.; Zoller, T.; Antoniazzi, F.; Piacentini, G.; Fearnbach, S.N.; Heymsfield, S.B. Effects of COVID-19 lockdown on lifestyle behaviors in children with obesity living in Verona, Italy: A longitudinal study. Obesity 2020, 28, 1382-1385. [CrossRef] [PubMed]

12. Chastin, S.F.M.; Palarea-Albaladejo, J.; Dontje, M.L.; Skelton, D.A. Combined effects of time spent in physical activity, sedentary behaviors and sleep on obesity and cardio-metabolic health markers: A novel compositional data analysis approach. PLoS ONE 2015, 10, e0139984. [CrossRef] [PubMed]

13. Guan, H.; Okely, A.D.; Aguilar-Farias, N.; del Pozo Cruz, B.; Draper, C.E.; El Hamdouchi, A.; Florindo, A.A.; Jáuregui, A.; Katzmarzyk, P.T.; Kontsevaya, A. Promoting healthy movement behaviours among children during the COVID-19 pandemic. Lancet Child Adolesc. Health 2020, 4, 416-418. [CrossRef]

14. Mandelkorn, U.; Genzer, S.; Choshen-Hillel, S.; Reiter, J.; Cruz, M.M.e.; Hochner, H.; Kheirandish-Gozal, L.; Gozal, D.; GilelesHillel, A. Escalation of sleep disturbances amid the COVID-19 pandemic: A cross-sectional international study. J. Clin. Sleep Med. 2021, 17, 45-53. [CrossRef]

15. Brazendale, K.; Beets, M.W.; Weaver, R.G.; Russell, R.P.; Turner-McGrievy, G.M.; Kaczynski, A.T.; Chandler, J.L.; Bohnert, A.; von Hippel, P.T. Understanding differences between summer vs. school obesogenic behaviors of children: The Structured Days Hypothesis. Int. J. Behav. Nutr. Phys. Act. 2017, 14, 100. [CrossRef] [PubMed]

16. Pinto, A.J.; Dunstan, D.W.; Owen, N.; Bonfá, E.; Gualano, B. Combating physical inactivity during the COVID-19 pandemic. Nat. Rev. Rheumatol. 2020, 16, 347-348. [CrossRef] [PubMed] 
17. Mitra, R.; Moore, S.A.; Gillespie, M.; Faulkner, G.; Vanderloo, L.M.; Chulak-Bozzer, T.; Rhodes, R.E.; Brussoni, M.; Tremblay, M.S. Healthy movement behaviours in children and youth during the COVID-19 pandemic: Exploring the role of the neighbourhood environment. Health Place 2020, 65, 102418. [CrossRef] [PubMed]

18. Leyton-Román, M.; Núñez, J.L.; Jiménez-Castuera, R. The importance of supporting student autonomy in physical education classes to improve intention to be physically active. Sustainability 2020, 12, 4251. [CrossRef]

19. Leyton-Román, M.; de la Vega, R.; Jiménez-Castuera, R. Motivation and commitment to sports practice during the lockdown caused by COVID-19. Front. Psychol. 2021, 11, 3846. [CrossRef] [PubMed]

20. Van de Mortel, T.F. Faking It: Social desirability response bias in self-report research. Aust. J. Adv. Nurs. 2008, 25, 40. 